\title{
Fundamental and derivative truths
}

\author{
J.R.G.Williams
}

(July 24, 2009)

\begin{abstract}
This paper investigates the claim that some truths are fundamentally or really trueand that other truths are not. Such a distinction can help us reconcile radically minimal metaphysical views with the verities of common sense.

I develop an understanding of the distinction whereby Fundamentality is not itself a metaphysical distinction, but rather a device that must be presupposed to express metaphysical distinctions. Drawing on recent work by Rayo on anti-Quinean theories of ontological commitments, I formulate a rigourous theory of the notion.

In the final sections, I show how this package dovetails with 'interpretationist' theories of meaning to give sober content to thought that some things- - perhaps sets, or gerrymandered mereological sums—can be 'postulated into existence'.
\end{abstract}

\section{Fundamentality as an expressive device}

In recent work, Kit Fine has suggested that we distinguish what really obtains from what merely obtains. The distinction applies, in particular, to existential statements. So it may be that some things exist, but don't really exist. A comparable distinction (which I here treat as equivalent) is the following: some things are fundamentally the case; other things are derivatively the case. Applied to existential claims: some things fundamentally exist; others exist derivatively. ${ }^{1}$

The task of the present paper is to outline one way of understanding this distinction, and to begin constructing a theory of how it behaves. To fix ideas it will be useful to have in mind some putative applications of the distinction:

\section{Composition: fundamental simplism with derivative arbitrary fusion (FSDA).}

Fundamentally, everything is a simple, microphysical particle. Derivatively, whenever there are some objects, they compose something. Tables, rocks, and chairs exist; but they are no part of fundamental reality. ${ }^{2}$

\footnotetext{
${ }^{1}$ Despite appearances, this is not supposed to introduce two 'kinds' of existence, any more than the common distinction between contingent and necessary existents introduces two kinds of existence.

Following Fine, I will speak of facts and employ the 'container' metaphor: of facts belonging or failing to belong to fundamental reality. But everything I say should be able to be interpreted using the sentential operator: It is fundamentally the case that $p$. So no commitment to an ontology of facts, or to reality as 'containing' or 'composed out of' these facts is intended. Compare (Sider, 2009).

Fine uses the framework for a variety of purposes. See in particular Fine (2005), paper 8 and especially Fine (2001).

${ }^{2}$ Compare van Inwagen (1990), Merricks (2001), Dorr \& Rosen (2002), Dorr (2002).

There is a serious empirical issue here about whether actuality (as opposed to some out-of-date Boylean image of actuality) is really consistent with an ontology of concrete microphysical simples. I do not wish to take a stand on this, though it is instructive to bear in mind the availability of Bohmian interpretations of quantum mechanics,
} 


\section{Set theory: fundamental nominalism; derivative sets (FNDS).}

Fundamentally, everything is concrete. Derivatively, the axioms of ZFCU hold good. The null set, and the set of readers of this essay exist; but they are no part of fundamental reality.

These doctrines will be controversial in their own right, even for one who accepts the fundamental/derivative distinction. Other set theories, or other material ontologies, might be put forward as describing the non-fundamental world. Equally, some would defend a less minimal take on what fundamentally exists. But the options just mentioned will serve our purpose of providing toy models for the application of our theory.

\subsection{Two interpretations}

Why believe in a distinction between fundamental and derivative truths? And, granting one believes in it, what sort of distinction is it?

Suppose there is a certain clash between metaphysics and common sense. For familiar reasons, one might dislike an ontology that includes causally inefficacious abstracta, or (allegedly!) causally redundant macroscopic entities. One takes oneself to have pro tanto reason for believing in a radical and minimal ontology: perhaps featuring only concrete, simple entities postulated by microphysics. ${ }^{3}$ On the other hand, one might also have direct arguments against errortheoretic interpretations of swathes of entrenched opinion, ${ }^{4}$, or for thinking that endorsing such an error-theoretic views would be irrational, ${ }^{5}$ or one might simply feel that an error-theoretic view grants dangerous hostages to fortune, and should be disliked on that account. Now, if the metaphysical arguments one offers can be construed as concerning fundamental ontology, then one can have one's cake and eat it: endorse the attractive package of a radically minimal metaphysics, while endorsing the (albeit non-fundamental) truth of the corpus of common sense belief.

So a fundamental/derivative distinction may reconcile apparently conflicting philosophical opinions. But independently of this, the distinction may do substantive theoretical work. Lewis (1983) argued that we need to distinguish between 'elite' properties (paradigmatically, charge and mass) and 'merely abundant' properties (paradigmatically, being grue). Such a distinction, he argued, was needed in the theories of physicalism, intrinsicality, laws of nature, counterfactuals, causation, dispositions, mental and linguistic content. Hirsch (1993) explores the case for positing a similar distinction between elite objects (like me?) and merely abundant ones (the fusion of a donkey's left leg and my ear). Sider (2009) has recently argued that to do the work that Lewis envisaged, we need to extend the distinction to entities of every kind: the elite/abundant distinction can be drawn for operators and quantifiers, modifiers and the like, as well as objects and properties. ${ }^{6}$

\footnotetext{
before leaping to the conclusion that the naive picture is refuted by contemporary physics. Notice, also, that the nihilist metaphysics need not claim that the concrete simples have determinate locations, nor even that it be determinate how many simples exist. This is not to minimize the threat to the classical picture from quantum field theory and the like. Ultimately, defending a nihilist ontology requires both empirical and more purely philosophical questions. Obviously, I believe it is methodologically legitimate to pursue bracket the empirical questions at least pro tem.

${ }^{3}$ See for example Merricks (2001). For a different sort of reason for favouring such a nihilist metaphysics, see Williams (2008).

${ }^{4}$ See Azzouni (2004, ch.2)

${ }^{5}$ Certain views on the status of so-called Moorean truths might have this result. See for example Kelly (2005).

${ }^{6}$ It is another question whether to draw the needed distinction we need to 'reify' the entities in question (in the property case, whether we need to be realists to draw our distinction). Sider (2009) argues that the nominalist can draw the needed distinctions without reification. Compare also Melia (n.d.).
} 
Given the trajectory of the debate, it is natural to consider a distinction between elite and non-elite facts. One might believe in such a distinction because one identified a distinctive theoretical role that could not be played by the multitude of elite/non-elite distinctions at the subsentential level. ${ }^{7}$ Or one might believe in the distinction because it is a way of unifying all the other distinctions for which Lewis, Hirsch, Sider and others argue. ${ }^{8}$ So if we have a fundamental/derivative distinction, there are pontential roles for it to play throughout metaphysics.

It is one thing to find a role and a reason for believing in the fundamental/derivative distinction. It is another to say what that distinction consists in. Consider the range of options that Lewis offers in explication of the distinction between elite and non-elite properties: the elite might be those which correspond to an Armstrongian Universal; they might be those whose instances are united by primitive resemblance; it might be, indeed, that the elite/non-elite distinction is itself metaphysically primitive. We can expect a similar range to emerge as a way of articulating the distinction between fundamental and derivative truths. For example, corresponding to the option of taking eliteness (or 'naturalness') as a metaphysically basic division amongst properties, one might take the operator it is fundamentally the case that as metaphysical bedrock. ${ }^{9}$

This sort of thoroughgoingly metaphysical reading of the distinction is not the interpretation that I pursue here. Rather than seeing Fundamentality as a metaphysical primitive, I would see it rather as at most a conceptual primitive. On the reading offered here, the role of the operator it is fundamentally the case that will be to allow expression of genuinely metaphysical theses about what there is. It is the burden of what follows to explain how this view of the matter can be spelled out, and this paper will develop a rigourous account. But it will help to have an indication of where we're going, and so to fix ideas I finish this section by sketching the guiding picture.

I think we can distinguish between true propositions and the way that reality is required to be for those propositions to be true. That this chair exists is a true proposition. But what is required, for this to be true, is that there are simples arranged chair-wise (so, at least, the believer in FSDA will claim). Likewise, that the set of whales is a subset of the set of mammals is a true proposition. But what is required, for this to be true, is that the whales be among the mammals (So the believer in FNDS will claim: and if they are a believer in FSDA as well, they might weaken this still further). Where $p$ is what is required for $q$ to be the case, I shall also say that the truth of $p$ supports the truth of $q$. I hope this notion of requirement or support is something on which readers will have at least an initial understanding. ${ }^{10}$

Suppose for the sake of argument that we can spell out non-trivial requirements for each sentence or proposition. That makes possible the following picture of the relationship between

\footnotetext{
${ }^{7}$ Consider, for example, Stalnaker's complaint that Lewis's theory of mental content requires a distinction between eligible and ineligible propositions (rather than properties) that he is unable to give.

${ }^{8}$ Perhaps being an elite property should be analyzed as being the property-element of an elite fact: so that the reason why charge is elite and grue is not, is that Sparky is charged is an elite fact, and $N$ is grue never is. Likewise, elite objects would be object-constituents of elite facts, elite quantifiers the quantifier-constituents of elite facts, and so forth.

Even if Fundamentality itself can't play this role, the resources in terms of which Fundamentality is explained might do so, in which case the overall framework is justified.

${ }^{9}$ This is, I believe, the way that Sider (2007b) reads Fine's proposal.

${ }^{10}$ Some might wonder how this notion relates to the notion of certain entities (facts, tropes, etc) making true the true propositions. I think the relation here is complex. On some versions (Cameron (2008a)) the truthmaking theorist is attempting to articulate what the truth of true propositions require in exactly the sense at issue here. A distinctive further commitment is that requirements are all ultimately requirements that certain entities exist (for discussion of why the truthmaker theorist might be tempted by this step, see Cameron (2008b)). I certainly don't want to commit here to the idea that requirements are all existential requirements: a requirement could well describe directly how things are and not just that such-and-such things exist.
} 
thought/language and reality. Reality contains objects having properties; enough to meet the requirements of each true sentence. Sometimes (when the requirements for a proposition to be true happen to match the surface form of the sentence expressing that proposition) the relationship will be rather direct. If reality contains a spin-up simple, the truth of there being a spin-up simple is thereby supported. However, what is required of the world for a proposition to be true needn't always be so direct. ${ }^{11}$ Arrange simples chair-wise, and we support not only the truth (directly) of the proposition that there are simples arranged chair-wise but also (indirectly) of the proposition that there exists a chair.

On this picture, it will be true to say that chairs exist. But, for the purposes of metaphysics, we're not just interested in what the true sentences or propositions are: we're interested in the way reality is, in the objects and properties and their arrangements that support the truth of the propositions. Only the propositions which most directly reflect this are fundamentally the case. Fundamentality isn't itself a part of the way reality is, as the propertied objects are: rather, it is a device we use to enable us talk about the contents of reality directly.

\subsection{Theoretical challenges}

Two things cry out for explanation here. The first is the contention that arrangements of propertied objects support the truth of a rich variety of propositions, including some which are apparently about objects other than the ones we start with (chairs, rather than simples arranged chair-wise; sets of whales, rather than the whales themselves). The second is the use of 'Fundamentality' as an expressive device for talking directly about the propertied objects. The explanation of the operator I leave till the end. But the former challenge is addressed now.

The challenge to the view just described is very simple. Consider the proposition that $\exists x \operatorname{Rock}(x)$. Does not the truth of that proposition require the existence of rocks? Didn't Quine teach us that to be is to be the value of a variable. Given that rocks need to be among the values of variables for $\exists x \operatorname{Rock}(x)$ to be true, aren't we thereby committed to rocks?

Quine indeed claimed that the mark of ontological commitment to a type of entity was that we quantify over things of that kind. In doing so, he was making a non-trivial claim. Why, antiQuineans wonder, are we not as committed to the universal Rock-hood, as the individual rocks themselves, in endorsing the truth of sentences such as 'there are rocks' or 'that is a rock'? Why, when looking at the semantics of such sentences, do we focus on the values of variables, and not on the values of nouns, predicates and quantificational expressions alike (the latter including, on a standard implementation, sets of the individuals we quantify over). ${ }^{12}$

Quine was giving an account - an elegant, but disputable one-of what is required of the world for a sentence to be true. In application to existential claims such as there are rocks, it gives the intuitively appealing result that what is required of the world for this truth is that there be rocks (and not, that the universal rock-hood exists).

What the defender of FSDA or FNDS needs is a rival account of what is required of the world for this or that sentence to be true. And in general, I contend that such a 'theory of requirements' is what is needed to make precise the sort of claims alluded to in the previous section. If our claim is that simples arranged chair-wise can support the truth of the proposition that there are chairs, then we need a theory of requirements for compound-object thought and talk that says that what is required of the world for 'there are chairs' to be true, is that simples

\footnotetext{
${ }^{11}$ We can say that a proposition $q$ directly supported by reality if the requirement for $q$ to be true is simply that $q$. Otherwise, it is indirectly supported. These notions will be replaced by more precise notions in the theory to be given.

${ }^{12}$ For general discussion of ontological commitment, see Quine (1953), Armstrong (1989), Azzouni (2004), Rayo (2007).
} 
be arranged chairwise. If our claim is that whales being among the mammals can support the truth of the proposition that the set of whales is a subset of the set of mammals, then we need a theory of requirements for set-theoretic thought and talk, that says that what is required for the truth of the latter is exactly that the whales be among the mammals.

What we now need, therefore, is a sense of how such a theory might go. It is easiest to start by finding a way of formulating precisely a Quinean theory of requirements/ontological commitment. We then use the same resources to formulate hetrodox variants.

\subsection{Formulating the Quinean theory}

A theory of what is required for the truth sentences will have to specify demands on the world appropriate to each of an infinite variety of sentences. ${ }^{13}$ Agustín Rayo (2008)has recently shown us how to present a theory of requirements in such a fashion. Following Rayo, let us use the notation $[p]_{w}$ to express that the world $w$ is such that $p$. The idea now is to formulate the requirements for $S$ to be true by way of a biconditional relating $S$ 's truth (at a world) to various conditions on $w .^{14}$

Given this notational convention, we are in a position to give a compositional Quinean theory of requirements for a syntactically simple language. ${ }^{15}$

\section{Language}

Our object language, $L$, consists of the following symbols:

1. singular constants ' $c{ }_{i}$ '

2. first-order variables ' $x_{i}$ '.

3. non-logical vocabulary: the one-place predicate letters ' $F_{i}$ '

4. the identity symbol '='

5. the quantifier-symbol ' $\exists$ '

6. the monadic operator ' $\neg$ '

7. the dyadic operator ' $\&$ '

8. the auxiliaries '(' and ')'.

\footnotetext{
${ }^{13}$ Hitherto, I have talked in terms of what the truth of propositions require. But I am now going to switch to what the truth of sentences requires. This has the advantage of avoiding distracting questions about the nature of proposition. However, I take it that everything I go on to say will transfer, mutatis mutandis, to the case of (structured) propositions.

Structured propositions have truth-conditions just as much as sentences do. Indeed, some would insist that to specify truth conditions for sentences, we should first pair the sentences with structured propositions, and then give a compositional semantics directly for the propositions. For the kind of semantics for propositions that I have in mind, and that would dovetail nicely with what is to follow, see Soames (1989).

${ }^{14}$ The 'such that' locution should coincide with what a world represents to be fundamentally the case. Thus one who believes in fundamental simplism should endorse [there are no macroscopic objects]@, though he might quite consistently think that there are macroscopic objects. The challenge - to be addressed below-is to explain how the latter can be actually true, given the former.

${ }^{15}$ Rayo (2007) often uses paraphrases into []$_{p}$ talk rather than axiomatic semantics to present various theses. However, he is explicit that one could represent the ideas in truth-conditional form.
} 
Singular constants and variables are called singular terms. Formulae are defined as follows: ${ }^{16}$

1. If ' $t_{i}$ ', ' $t_{j}$ ' are singular terms, then ' $t_{i}=t_{j}$ ', ' $F_{i}\left(t_{j}\right)$ ' are formulae.

2. If ' $v$ ' is a (singular or plural) variable and ' $\phi$ ' is a formulae, then ' $\exists v \phi$ ' is a formula.

3. If ' $\phi$ ' and ' $\psi$ ' are formulae, then ' $\neg \phi$ ' and ' $\phi \& \psi$ ' are formulae.

4. Nothing else is a formula.

A sentence is a formula with no free variables.

\section{The theory of requirements}

Here is a theory of requirements for sentences in $L$. It takes the form of a specification of a semantic theory for $L .{ }^{17}$ In general, we write ' $\bar{F}$ ' for the translation into the metalanguage, of the object-language predicate ' $F$ '. Suppose our object-language is French, and the metalanguage English. Then if ' $F$ ' is 'chien', ' $\bar{F}$ ' is 'dog'. Likewise ' $\bar{c}$ ' is the translation into the metalanguage of the object-language constant ' $c$ '. So if ' $c$ ' is 'Londres', ' $\bar{c}$ ' is 'London'.

We start with the following:
A. The $w$-referent of $c_{i}$ is $x$ iff $\left[\dot{x}=\bar{c}_{i}\right]_{w}$.
B. The $w$-extension of ' $F$ ' is $X$ iff $X=\left\{x:\left[\bar{F}_{i}(\dot{x})\right]_{w}\right\}$
C. The $w$-domain is $D$ iff $D=\left\{x:[\exists y(y=\dot{x})]_{w}\right\}$

(Recall, the bracket notation $[p]_{w}$ expresses the requirement that world $w$ being such that $p$ ). Next, we introduce the notion of a variable assignment:

A variable assignment is a function that assigns to each ordered pair $\left\langle{ }^{\prime} x_{i}{ }^{\prime}, w\right\rangle$ an object $z$ such that $z \in D$.

Finally, we characterize the notion of truth relative to a variable assignment $a$ and a world $w$ (equivalently, satisfaction) in the following way:

1. (a) ' $F_{i}\left(c_{j}\right)$ ' is true at $a, w$ iff the $w$-referent of ' $c{ }_{j}$ ' is a member of the $w$-extension of ' $F_{i}$ ';

(b) ' $F_{i}\left(x_{j}\right)$ ' is true at $a, w$ iff $a\left(\left\langle{ }^{\prime} x_{i}^{\prime}, w\right\rangle\right)$ is a member of the $w$-extension of ' $F_{i}$ ';

2. (a) ' $x_{i}=x_{j}$ ' is true at $a, w$ iff $a\left(\left\langle{ }^{\prime} x_{i}, w\right\rangle\right)$ is identical to $a\left(\left\langle{ }^{\prime} x_{j}, w\right\rangle\right)$;

(b) ' $x_{i}=c_{j}$ ' and ' $c_{j}=x_{i}$ ' are true at $a, w$ iff $a\left(\left\langle x_{i}^{\prime}, w\right\rangle\right)$ is identical to the $w$-referent of ' $c{ }_{j}$ ';

3. (a) If ' $v$ ' is a singular variable and ' $\phi$ ' a formula, then ' $\exists v \phi$ ' is true at $a, w$ iff ' $\phi$ ' is true at $a^{\prime}, w$, where $a^{\prime}$ differs from $a$ at most in assigning some $x$ in the $w$-domain to $\langle ' v ', w\rangle$.

\footnotetext{
${ }^{16}$ Single-quotation marks should be read as quasi-quotes in what follows.

${ }^{17}$ Aside from the bracket notation, the only non-standard element of the theory is the use of dots above variables within brackets, when they are bound by quantifiers occurring outside the brackets. This is a technical device in the metalanguage that for most purposes can be ignored. Full details and a semantics for the metalanguage are presented in the appendices to Rayo (2008).
} 
(b) ' $\neg \phi$ ' is true at $a, w$ iff ' $\phi$ ' is not true at $a, w$

(c) ' $\phi \& \psi$ ' is true at $a, w$ iff ' $\phi$ ' and ' $\psi$ ' are true at $a, w$

Finally, the definition of 'truth' simpliciter: 18

T. For any sentence $S$ of $L, S$ is true iff it is true at the actual world, @, on all variable assignments

\section{Extracting requirements}

Recall that the bracket notation $[p]_{w}$ is meant to express the requirement that $p$ is true in $w$. What we are looking for is a way to find, for each sentence $S$, conditions on what the actual world @ must be like for $S$ to be true. ${ }^{19}$ Let us think first about a specific case, that of the sentence 'Billy sits'. From:

- 'Billy sits' is true

by axiom $(T)$ we then get:

- 'Billy sits' is true at all $a$ and world @

by axiom (1) we then get:

- the @-referent of 'Billy' is a member of the @-extension of 'sits'

but instances of schemas (A) and (B) are:

$A_{\text {Billy }}$ The @-referent of 'Billy' $=x$ iff $[\dot{x}=\text { Billy }]_{@}$

$B_{\text {sits }}$ The @-extension of 'sits' $=X$ iff $X=\{z:[\operatorname{sits}(\dot{z})] @\}$.

From these and the above we get:

- the $x$ such that $[(\dot{x}=$ Billy $)] @$ is a member of $\{z:[\operatorname{sits}(\dot{z})] @\}$.

This is the canonical statement for what is required of @ in order that 'Billy sits' be true.

Two questions arise. First, does this generalize to arbitrary sentences $S$ ? Second, what does the canonical statement we end up with say?

Under examination, it isn't too difficult to see how to generalize the technique. In each case, we start from the statement that $S$ is true, and then reach a canonical statement by a series of equivalences given to us by the axioms above. The recipe is as follows. We first appeal to $(T)$, and then appeal to the compositional clauses (1-3) in a way reflecting the syntactic build-up of the sentences, to end up a statement of what $S$ 's truth requires in terms of relation between the@-referents and @-extensions, of the non-logical terms that $S$ contains (along with

\footnotetext{
${ }^{18}$ To define consequence for this language, we would further relativize the definition of truth at $a$ and $w$ to an model giving a domain $d$ and an interpretation $i$ that assigns to each term and predicate a function from worlds to objects/extensions. In place of ' $w$-referent', ' $w$-extension' and ' $w$-domain' in clauses 1-3, one would use the value of function assigned by $i$ to the name/predicate at $w$, and the domain of the model. Truth would then be identified with truth at the intended interpretation/model. To specify the intended interpretation and model, we would use the notions of $w$-referent, $w$-extension and $w$-domain: the intended interpretation should assign to ' $c_{i}$ ' a function that maps each world $w$ onto ' $c_{i}$ 's $w$-referent, as characterized above; and similarly for predicates and the quantifier. I have suppressed the relativity to interpretations just to minimize complexity in stating the theory.

${ }^{19}$ Why only @? Well, since the object language we're working with doesn't contain modal terms, this issue won't arise. But in general it will raise some interesting issues-see below.
} 
the $w$-domain). Once we've got to this point, we can appeal to relevant instances of the axioms $(A-C)$ to convert the talk of @-referents and @-extensions to talk of requirements on the world formulated in terms of the bracket notation. ${ }^{20}$

This general recipe lets us derive a biconditional relating the truth of some $S$ to some claim formulated in terms of the distinctive bracket-notation. But what does this say? We can use the above sentence as a case study. In the case, the claim biconditionally related to the truth of 'Billy sits' is:

$$
\text { the } x \text { such that }[(\dot{x}=\text { Billy })] @ \text { is a member of }\{z:[\operatorname{sits}(\dot{z})] @\}
$$

This we read as requiring that there be some $x$ such that (i) the (actual) world is such that $x$ is Billy; and (ii) $x$ is a member of the set of things that, in the actual world, are sitting. ${ }^{21}$

In general, if we interpret each clause of the form ... $[p]_{@} . .$. as the requirement that the actual world - the reality we inhabit—be such that $p$, we have a statement of what reality must be like for the sentence $S$ to be true. ${ }^{22}$

\subsection{Sets}

Let us note one crucial feature of that face-value reading. What is required for the truth of 'Billy sits' is inter alia that reality contain Billy, and contain sitting things. However, there is no requirement that reality contain sets. This reflects a distinctive Quinean claim - that statements like 'Billy sits' do not commit one to the semantic values of predicates (in this case, sets), though they do commit one to things that sit. Anti-Quineans have disagreed: maintaining that 'Billy sits' commits us, inter alia to the property of sitting, or to the set of things that sit.

This point is vital, and perhaps not obvious at first glance. After all, the canonical statement of the requirements that we have arrived at does talk about sets: Billy has to be a member of the set of things that are sitting at @. However, this is just to note that we use sets to express what the requirements on reality are, not to say that the existence of sets is part of what is required for 'Billy sits' to be true. ${ }^{23}$

\footnotetext{
${ }^{20}$ To formalize this story would be a task analogous to identifying the 'interpretative T-sentences' within a Davidsonian truth theory. See for example Larson \& Segal (1995).

${ }^{21}$ See Rayo (2008). The reading of the bracketed formula just given corresponds to what he calls the 'secondary' condition expressed by bracketed formulae.

${ }^{22}$ One might object that the instructions given are only partial-since they tell us only how to make sense of brackets relativized to @, whereas more generally brackets will be relativized to (possibly non-actual) w. This will be a worry only if we actually are faced with the challenge to interpret statements of requirements which relativize brackets to something other than @. For the languages in the paper, this issue will not arise, and so the instructions above are complete as they stand.

Relativization to worlds other than @ can arise if (i) one includes world-shifting (i.e. modal) operators in the object-language; (ii) if the axioms for what basic expressions refer-to-at- $w$ invoke worlds other than $w$. When we are working with an object language for which neither of the above arises, then it is straightforward to see that the canonical statement of the requirements for $S$ to be true-at-@ conditions are formulated entirely in terms of brackets relativized to @.

There remains the question of how the approach would be extended to deal with possible theories of requirements, for example for modal object-languages. I contend, that the instruction above is still complete even for such extended languages. However, it is conceptually quite tricky to see what the theory of requirements is saying in such a setting. This is a difficult question, and one best delayed until we have explored the what the theory says about the basic case.

${ }^{23}$ If I ask you to bring me everything that is a member of the set of edible things in the fridge, then I've formulated a request that is met when you bring me everything edible in the fridge. The set is involved in formulating the request, not part of what is requested.
} 
A central idea of the theory of requirements is that there is a scope ambiguity in such statements as: "the requirement for "Billy sits" to be true is that Billy be a member of the set of things that are sitting in @'. That statement could be regimented as either of the following:

In @, Billy $\in\{x: x$ sits $\}$

Billy $\in\{x:$ In @ $\mathrm{x}$ is sitting $\}$

or, in the official idiom:

$[$ Billy $\in\{x: x$ sits $\}] @$

Billy $\in\{x:[\mathrm{x}$ is sitting $] @\}$

In the first formulation, the requirements on @ include the existence of a certain set-the set abstraction scopes under the brackets or 'in @'. In the second formulation on the other hand, the scope is reversed. The brackets have narrower scope than the set abstraction, and consequently it is no part of what is required of @ that sets exist. In principle, we can build a theory of requirements around either disambiguation. ${ }^{24}$ But if we want to capture the distinctive Quinean thought then it is crucial that we resolve the scope ambiguity in the second way. If we do so, then commitment to sets only comes in when we say things like 'there are sets' and not when we say things like 'Billy sits'. ${ }^{25}$ The main use of the bracket notation $[p]_{w}$ is as a device for making these scope-distinctions explicit. ${ }^{26}$

\footnotetext{
${ }^{24}$ Or at least: we can build a theory of requirements that generates a difference in commitments analogous to the above difference. The key move is in the formulation of the predicate-axiom. The version of the predicate axiom above allows us to derive commitments with the narrow-scoped brackets form just given. We will end up with a different requirement if we start instead with the following axiom for predicates:

such as
}

The $w$-extension of ' $F_{i}$ ' is $X$ iff $\left[X=\left\{x: \bar{F}_{i}(x)\right\}\right]_{w}$

The requirement on sentences that derived from a theory of requirements containing this 'wide-scope' predicate axiom is then:

$$
\exists x \exists X\left([x=B i l l y]_{@} \&[X=\{x: x \text { sits }\} \& x \in X]_{@}\right)
$$

This isn't exactly the same as the wide-scoped requirement given in the text. But the more complex form exhibited here requires of @ that it contains sets-just as simpler one does.

Many thanks to Robert Schwartzkoff for pressing me on these issues.

${ }^{25}$ I say the Quinean thought rather than Quine's thought, because it is not at all obvious that Quine himself would accept some presuppositions of this setting-in particular the set-theoretic and worlds semantics. Quine has a distinctive take on how one should theorize about language, and the kind of set-theoretic 'intended interpretations' don't have any obvious place in it (there is of course a role for interpretations in general, as part of a modeltheoretic characterization of consequence). But the Quinean views on ontological commitment which are by far the orthodoxy surely should not be tied to these controversial positions in the philosophy of language-and anyone who has some sympathy for a set-theoretic intended interpretation for natural language will have to make the sort of distinctions given in the text, to maintain the orthodox Quinean position on ontological commitment.

${ }^{26}$ One can see the distinction more clearly if one imagines formulating the demands, not in terms of what has to be true in actuality for 'Billy sits' to be true at @ , but what has to be true at some non-actual $w$ for 'Billy sits" to be true at $w$. If, for example, sets existed in the actual world, but $w$ was a 'nominalistic' world containing no abstract objects, still the demands for the truth of 'Billy sits' given above could be met. For, given that sets actually exist, we can perfectly meaningfully talk about the (actual) set of things that are (in w) sitting, and ask whether Billy is in that set or not. (We can suppose that $w$ and @ share all concrete ontology, so that no complications emerge as to whether the impure set of things that are sitting in $w$ itself exists in @.) This dramatizes one consequence of the Quinean way of resolving the scope ambiguity described above. Resolving the ambiguity in the opposite direction - and so including the existence of the set-of-sitters among what is required for 'Billy sits' to be truewould make that sentence automatically false at nominalistic worlds like $w$. 
This concludes our sample 'theory of requirements', for the non-modal object-language we're working with above. It gives an introduction to the key technical device in the theories that follow - the bracket notation. But it also articulates what I take to be the orthodox Quinean position on ontological commitment, and so forms a reference point for comparison with the hetrodox accounts of ontological commitment to follow.

\subsection{Anti-Quinean theories}

The Quinean view unifies where other theories would draw distinctions. Here are two ways of characterizing the philosophical task of metaphysics: (1) the investigation of what there is and how it is. (2) the investigation of reality; of the fundamental nature of things. (1) might be called 'metaphysics-lite'; (2) might be called 'metaphysics proper'. If Quine is right, then there is no distinction to be drawn here: what exists, is what really exists. Talk of 'fundamental reality' is redundant, and metaphysics lite and metaphysics proper amount to the same thing. ${ }^{27}$ Without the Quinean account of ontological commitment, and more generally the Quinean theory of requirements just sketched, we cannot assume that (1) and (2) characterize the same task. In this and the following sections, we examine ways in which this can happen.

The views under consideration are anti-Quinean, in that they say, for example, that the truths there are tables, the set of whales is a subset of the set of mammals require of the world far less than initial appearances suggest. One option in formulating such theories would be to try tweaking the clauses in the Rayo-style Quinean theory just given. A crucial clause in the Quinean theory is that the semantic value of 'Billy', maps a world $w$ to $x$ iff $[\text { Billy }=x]_{w}$. The demand on the world expressed in the right hand side of the biconditional feeds through to the claim that for 'Billy sits' to be true, the world is required to contain Billy. A natural thought, therefore, is to substitute some other weaker condition in the original clause. We might try the following: the semantic value of 'Billy' is a function that maps a world $w$ to $x$ iff $x$ is the fusion of $X$, and $[\operatorname{arranged-Billy-wise}(X))]_{w}$. The eventual requirement on the world for 'Billy sits' will only be that the world contain some things arranged Billy-wise (and, with analogous adjustments elsewhere, that these things also be arranged sitting-wise).

Notice that Billy is still assigned as the extension of the name at each world meeting the requirement. What is important is that the clauses inside square brackets be free of mention or quantification over complex objects. The fact that a compound object such as Billy is assigned as the semantic value of some name no more makes the truth of sentence containing that name require that Billy exist, than the assignment of a set as the semantic value of a predicate within the Quinean theory makes the truth of sentences involving that predicate require the existence of sets. In each case, the metalinguistic sentence stating what the requirements are may yet be committed to compound objects or sets-but the theory says that the object language sentence simply is not. ${ }^{28}$

How in detail would such an anti-Quinean theory go? In what follows, I will outline how such a theory might be formulated. ${ }^{29}$

\footnotetext{
${ }^{27}$ Of course, that is not to say that one who is Quinean on this point might not want to draw distinctions within the class of (really) existing things: Lewis's natural/non-natural distinction, discussed earlier, is one such method.

${ }^{28}$ Of course, it is natural in this setting to reapply the story to the metalanguage itself, to say that even this usage is non-committal. But it is important to realize that these are separate issues.

${ }^{29}$ This will not, in fact, follow the proposal just given, of stating the requirements for 'Billy' to refer to objects in terms of pluralizations such as 'arranged-Billy-wise'. Theories of the latter form can be given, but are subject to certain in-principle limitations, of a kind with the limitations that Uzquiano (2004) describes for van Inwagen's paraphrase project. The view to be developed below does not suffer such limitations.
} 


\subsection{A non-Quinean theory of requirements}

It is vital to the very formulation of a theory of requirements that we appeal a notion of $w$ being such that $p$. Whichever way we express it, the notion is at the root of the theory of requirements. It is this that we formulate with the bracket notation: that $p$ is the case according to $w$ is expressed as $[p]_{w}$. Our non-Quinean theory involves certain constructions from this basic notion. While we can think of $[p]_{w}$ as telling us what a world represents to be the case, the non-Quinean theory will be formulated in terms of what a world pseudo-represents to be the case. ${ }^{30}$ Talking of ' $w$ representing that $p$ ' instead of ' $w$ being such that $p$ ' enables me to formulate the comparison more clearly, but I intend the two phrases to be equivalent.

Given this notion of what $w$ represents, there is no obstacle to us stipulatively defining other notions. For example, let us say that a world will contra-represent that $\neg p$ iff $[p]_{w}$. Contrarepresentation is a well-defined notion. The actualized world, for example, is a world at which there are chairs; but it contra-represents that there are no chairs.

Another toy example. Let us say that a world $w N$-represents that $q$ iff for some $p,[p]_{w}$ and the following holds:

$$
\text { ( } p \& \text { There are at most } N \text { things) } \Rightarrow q
$$

Now, if the actual world contains no more than $N$ things, then it $N$-represents all and only what is the case at $w$. But if reality contains more than $N$ things, then the actual world will $N$-represent absurdity: every proposition whatsoever. For it will represent there are more than $N$ things, and substituting this for $p$ in the above gives us that the actual world $N$-represents everything that follows from an explicit contradiction.

Contra-representation and N-representation are not suited to do valuable theoretical work. But they illustrate the possibility of stipulatively defining new 'pseudo-representational' properties of worlds. In what follows, the project is to construct notions of pseudo-representation which will help us formulate our theory of requirements.

To do this, we need to get clear on what the relata of the pseudo-representation relation is. Since the central issues arise already for $N$-representation, we shall explore them first in this context before defining the theoretically useful pseudo-representation properties. $\mathrm{N}$ representation certainly seems to be well-defined - the question is simply how best to articulate it.

The bracket notation gives us a sentential operator-adjoining to sentential clauses to make a complete sentence. We have also quantified into sentence-position above in characterizing $\mathrm{N}$-representation. One theoretical treatment of the representation relation is that it holds between worlds and propositions, and that we understand quantification into sentence-position as quantification over propositions. Thus the definition of $N$-representation may be represented as follows:

$$
\begin{aligned}
& N \text {-represents }(w, q) \text { iff } \\
& \exists p\left([p]_{w} \&(p \& \text { that there are at most } N \text { things })\right) \Rightarrow q
\end{aligned}
$$

\footnotetext{
${ }^{30}$ The talk of worlds representing this or that is familiar from accounts of worlds on which they are abstract representations. Even Lewis thinks of his concrete worlds as representations-albeit representations that work rather differently to languages or pictures. This is the key, for example, to his treatment of transworld identity: no other possible world contains me; but other worlds can be such that I exist, that is, represent that I exist, in virtue of containing my counterparts.

Of course, with the distinction between fundamental and derivative truths in mind, there's a question about whether everything true at $w$ will be represented by $w$. I'm taking it that what is represented by $w$ is coextensive with what is fundamentally true at $w$.
} 
This presupposes three things (i) some background theory of propositions; (ii) a worldproposition relation expressed by the brackets; (ii) an entailment relation among propositions $\Rightarrow$.

One might be uncomfortable with the appeal to propositions here involved. A different way of regimenting the above characterization of $\mathrm{N}$-representation would involve a metalinguistic characterization of a new operator ' $N$-represents', as follows:

' $w N$-represents that $p$ ' is true iff

There is some ' $q$ ' such that ' $[q]_{w}$ ' is true and

$\{' q$ ', There are at most $N$ things' $\} \Rightarrow$ ' $p$ '.

Here the quantification is over linguistic expressions (though the brackets still express sentential operators, not a world-sentence relation) and the entailment involved relates sentences. ${ }^{31}$

Whether one of these formulations is ultimately preferable to the other will depend largely on background commitments-what one thinks propositions are, what notions of entailment are available among them, what one's theory of world-representation is. However, methodologically there is some advantage with formulating the proposal in the second way, since what sentences are and what consequence relations hold between them, are less contentious than the corresponding issues about propositions. We shall therefore adopt the sentential strategy in what follows.

Of course, the construction of $N$-representation from representation simpliciter will only be well-defined once we have said what the entailment relation $\Rightarrow$ is to be. For the purposes of $N$-representation, we can take it to coincide with a narrow notion of logical consequence (characterized, for example, in the Tarskian model-theoretic way). In more interesting applications, it will matter crucially exactly what this relation is.

\subsection{Theoretically useful pseudo-representation}

Contra-representation and $N$-representation are not terribly interesting, but other pseudo-representation properties can do valuable theoretical work. Let me flag an immediate issue. Pseudo-representation properties are extremely cheap. We have already seen contra- and $N$-representation. We can let our imagination rip, and define all sorts of other properties. What is significant is not that we can define this or that relation, but that we use it within wider theory, and defend this use. I here develop some pseudo-representation properties that will prove theoretically useful, and then use them to formulate a theory of requirements. In later sections, I will defend the use of these particular pseudo-representation properties, and address the concern that the strategy sketched below is underconstrained. For the moment, I ask readers to put such wider worries aside, and simply concentrate on the construction itself.

Let us begin by defining a paraphrase relation among sentences. For each $S$, let $\tilde{S}$ be the result of restricting every quantifier in $S$ with the previously uninterpreted predicate $B$ (for 'basic'). Let $Z F C U$ be a axiomatization of set theory together with urrelemente. Let $M$ be a classical, extensional theory of mereology together with an axiom of unrestricted composition. Given this, consider the following pair of definitions:

1. ' $w$ compound-represents that $q$ ' is true iff there is some ' $p$ ', such that ' $[p]_{w}$ ' is true, and $\left\{{ }^{\circ} \tilde{p},, M\right\} \Rightarrow ' q$ '

\footnotetext{
${ }^{31} \mathrm{~A}$ rival to both of these is to take the sentence-position quantification at face value, as a sui-generis kind of higher-order quantification (and not, e.g. objectual quantification over propositions). See for example Williamson (2003) for defence of this in a different setting.
} 
2. ' $w$ set-represents that $q$ ' is true iff there is some ' $p$ ', such that ' $[p]_{w}$ ' is true, and $\{$ ' $\tilde{p}$ ', $Z F C U\} \Rightarrow$ ' $q$ '

Let us suppose that reality contains no abstract objects (in particular, no sets) and nothing but simple objects. The actual world will represent there being no sets, and no compound things. But, it will compound-represent there being fusions of simples arranged chair-wise, and setrepresent the existence of impure sets of objects.

Of course, we might want to combine these two, to construct some pseudo-representation relation such that the actual world will in that sense pseudo-represent the existence of sets of compound objects:

3. ' $w$ set-compound-represents that $q$ ' is true iff there is some ' $p$ ', such that ' $[p]_{w}$ ' is true, and $\{$ ' $\tilde{p} ', Z F C U+M\} \Rightarrow$ ' $q$ '

We introduce notation for pseudo-representation analogously to Rayo's bracket notation: $w$ *-represents that $p$ iff $[p]_{w}^{*}$.

What sorts of things are pseudo-represented to be the case? It depends, to a great extent, on what exactly we appeal to in giving the definitions above. The more we pack into the set theory and mereology, and the richer the entailment relation, the more things will be compound- or set-represented to be the case.

As an extreme example, suppose $\Rightarrow$ is narrowly logical, first-order consequence (as given, for example, by Tarksi-style model-theoretic characterization), and ZFCU is a first order formulation of set theory with urrelemente. Even if in @ there are really no sets, existential-statements claiming the existence of infinitely many pure sets will be set-represented to be the case. Likewise, depending on what concreta exist at @, @ will set-represent the existence of many impure sets.

There is not a lot more to ordinary thought and talk about impure sets, one would think, than follows logically from ZFCU and the nature of the urrelemente themselves. So this minimal take on what set-representation seems at least a good starting point. ${ }^{32}$

By contrast, intriguing questions arise about the ambition and achievement of compoundrepresentation. Minimally, a nihilist reality will compound-represent the existence of fusions of things arranged table-wise. But will reality compound-represent these fusions as being chairs? Will it even represent these fusions as located where their parts are? Classical extensional mereology with unrestricted fusion tells us about what compound objects exist and their mereological structure. But it doesn't by itself say anything about the extra-mereological properties of those compound objects. All sorts of hypotheses about the location of composites are narrowly logically consistent with bare mereology.

Two ways forward present themselves. We could pack into $M$ inheritance principles for locations of composites and other properties - conditionals relating the properties of fusions to the properties of their parts. ${ }^{33}$ In a piecemeal way, we can thereby enrich what is compoundrepresented to be the case, and never appeal to anything more controversial than narrow logical consequence.

\footnotetext{
${ }^{32}$ The principal issue, I take it, will be over first-order incompleteness - in particular, Gödel sentences. The folklore has it that these are intuitively true-however, they are probably not first-order consequences of ZFCU, and so on the above articulation, will not be set-represented to be the case. To address such questions, one might switch to second-order ZFCU, and second-order consequence (Shapiro, 1991). There may well still be incompleteness in the theory (though see McGee (1997) for a connection between this and issues of unrestricted quantification). Some of the incompleteness - to do, for example, with GCH and large cardinal axioms-will be discussed below. For an alternative take on the status of Gödel sentences, see Field (1998).

${ }^{33} \mathrm{Cf}$. Sider (2007a) for lists of some of the sorts of principles we might include here.
} 
My preference, however, would be to enrich $\Rightarrow$ itself. Rather than taking this to be narrowly logical entailment, one can take it to consist in a priori entailment. ${ }^{34}$ I take it that it follows $a$ priori that a fusion of things arranged table-wise is a table, and that its location and properties are related in the obvious ways to the locations and properties of its simple parts. Given this, if @ says that some things are arranged table-wise, it will compound-represent (in this rich sense) the existence of a table with most of the properties one would ordinarily want to attribute to it. ${ }^{35}$

In what follows, I will assume that we have a rich notion of compound-representation available. That means that one way of attacking the letter of what is to follow is bring in general objections to a priori entailment. It is therefore important to note the various fall-back positions: (i) narrow logical consequence arguably suffices for certain interesting applications of the overall conception (in particular, the set-theoretic case); (ii) even if the pure theory of mereology + narrow logical consequence doesn't suffice, supplementing the pure theory of mereology with various explicit 'inheritance' principles may well suffice. Personally, I am comfortable appealing to a priori entailment. Those with scruples in this regard should feel free to explore alternatives.

\subsection{Piggybacking on the Quinean theory}

Finally, we turn back to the formulation of a theory of requirements for a language whose subject-matter appears to include compound objects or sets. The idea is very simple: instead of formulating the Quinean theory as a theory of requirements directly (i.e. what the actual world must represent to be the case), we formulate it as a theory of pseudo-requirements.

For example, in place of the atomic clauses, we will write:

$$
\begin{aligned}
& \mathrm{A}^{*} \text {. The } w \text {-referent of } c_{i} \text { is } x \text { iff }\left[\dot{x}=\bar{c}_{i}\right]_{w}^{*} \text {. } \\
& \mathrm{B}^{*} \text {. The } w \text {-extension of ' } F_{i} \text { ' is } X \text { iff } X=\left\{x:\left[\bar{F}_{i}(\dot{x})\right]_{w}^{*}\right\}
\end{aligned}
$$

In place of the previous $[p]_{w}$ which told us what $w$ was actually like, $[p]_{w}^{*}$ is to be read via one of the pseudo-representation properties: for example as $w$ compound-represents that $p$.

\footnotetext{
${ }^{34}$ Other options that might do a similar job would be broadly logical entailment, conceptual entailment, or analytic entailment. I'm inclined to think that these notions come to more-or-less the same thing, though whether they are as strong as a priori entailment is another matter. In Tarskian terms, such notions can be thought of as corresponding to truth-preservation in all models of the language that are consistent with the actual meaning that the expressions have.

I assume that a notion of a priori entailment among sentences is available. This might be a matter, for example, of some corresponding conditional sentence expressing a necessary primary proposition (cf. e.g. Chalmers (2002)). The notion may take some finessing-for example, some argue that certain inductive inferences may be count as a priori (so that a priori entailment would be non-monotonic) (Hawthorne, 2002).

If that is right, I will construct a stronger notion of a priori entailment for my purposes-roughly, $A$ will a priori entail $B$ in the strong sense iff $\Gamma, A$ a priori entails $B$ in the weak sense, no matter how we fill in $\Gamma$. (As mentioned above, there is the fallback option of appealing to analytic, rather than a priori, entailment).

${ }^{35}$ As a referee notes, one might well take it to be a priori in the current setting that whenever there are some things arranged table-wise (say) that there is some object that they compose (this is of course a different claim to that appealed to in the text-that if some things are arranged table-wise, and they compose, then that thing which they compose is a table). I think I can afford to remain agnostic on this issue. If the composition principle is a priori, then at most there will be a certain redundancy in the definition of compound-representation-as far as I can see, there will be no conflict.

What would be damaging is if someone claimed that it was a priori that composition did not occur in such circumstances - but clearly that claim is already in tension with the overall non error-theoretic project investigated here. To avoid an error-theory, it at least needs to be true that there are tables (and that they are composed of the things arranged table-wise) — and so it cannot be a priori that no table-composition occurs.
} 
When we unwind the 'requirements' for the truth of 'Billy sits' as before, therefore, we find the following:

- $\exists x\left([\dot{x}=\text { Billy }]_{@}^{*}\right.$; and $x$ is a member of the set of $z$ such that $[\operatorname{sitting}(\dot{z})]_{@}^{*}$.

Thus, the truth of 'Billy sits' requires that the actual world compound-represent the existence of Billy; and that Billy be one of the set of $z$ such that the actual world compoundrepresent it as sitting. What, then, must hold at reality, in order for this to be the case? That is, what must the actual world represent to be the case, in order for it to compound-represent the above? Well, in general, it must represent that $p$ for some $p$ such that from $\tilde{p}$ together with Mereology, it follows that Billy exists and is sitting. In this case it suffices for this that there be some simples arranged Billy-wise - for then, given mereology, it follows Billy exists-and that these simples are arranged sitting-wise-for then, given mereology, it will follow that he sits.

The way that ontological commitments are evaded by the theory of requirements set up via pseudo-representation is reminiscent of various fictionalist proposals for carrying out the same job. To contrast it with other ways of deploying the theory of requirements, it wouldn't be inaccurate to label the position fictionalist. But the pseudo-representation story just given has no truck with any kind of syntactic or semantic revisionism - there is no trace in the current story of tacit fictive operators, or proposing that words don't refer or apply to the things that one would expect. Furthermore, there is no trace of an error-theory: 'compound objects exist' is trueperiod. So this is not a story where literal content comes apart from fictive or metaphorical content, with the world satisfying the latter but not the former. In later sections, we will be elaborating a positive proposal for what the world and language-users have to be like for a pseudo-representation based theory of requirements to be correct-and it will be no part of that story that we are engaging in a game of make-believe in speaking a language properly characterized in the way just sketched. ${ }^{36}$

\footnotetext{
${ }^{36}$ Steve Yablo's fictionalist proposals makes for an interesting comparison and contrast. One key part of Yablo's framework is the notion that sentences have (in addition to their literal content) real content (Yablo, 2001). Very roughly, real content of $S$, relative to some fiction $F$ is what condition the world must meet, given that $F$ holds, to make $S$ true. (This is object-fictionalism in Yablo's sense. He discusses it and proposes some refinements in Yablo (2001)).

The relationship between Yablo's 'literal content' and his 'real content' is analogous to that proposed here between 'what is required*' (e.g. what @ must pseudo represent to be the case) and 'what is required' (what @ must represent to be the case). Both contrast, for example, with what Yablo (2001) calls metafictional proposals, where $S$ has some conditional content of the form According to the fiction, $S$.

However, I find it hard to map the proposals onto one another. Obviously the theoretical setting is very different. As I read him, Yablo's 'literal content' is the content compositionally determined by the semantics of language (it could then equally be called 'semantic content'). However it is the real content of the sentence which is asserted in typical assertoric utterances of the sentence. If so, there is a good sense that when I utter the words 'the number of planets is eight', for Yablo the sentence uttered is untrue-even though what is thereby said may be true (cf. e.g. Yablo (2006, esp. fn.19) where sentential truth value and truth-conditions of assertoric content are clearly distinguished as such). There is a clear sense, then, in which Yablo's theory will count as a sophisticated errortheory. The current proposal is in no sense error-theoretic.

Connectedly, whereas for Yablo, there are multiple contents of the same theoretical kind interestingly related to 'the number of planets is eight'-its real content and literal content being conceived as distinct propositions (see e.g. Yablo (2000, §XIII) — on the current proposal there is (for all we have said) just a single proposition associated with the sentence, and in addition there is an answer to a question of a rather different kind-the question of what is required of the world for the sentence to be true. The theory of requirements is a way of answering the second question by way of giving an axiomatic theory specifying the proposition associated with each sentence. Such differences will ramify when we consider how the theories interact with the wider context—with metasemantics, or the theory of linguistic competence, or psychology of language use.
} 


\subsection{Fundamentality}

The construction of pseudo-representation is a very general tactic for creating a theory of requirements that will vindicate the idea that there can be truths which require of the world strictly less than a straightforward understanding of their subject-matter would suggest. We have seen in this way, that set-theoretic propositions and compound object-propositions can plausibly be true, without any requirement that the world contain compound objects or abstracta.

Sets and compound objects exist then-one expresses a true proposition by saying so-but the whole point of the enterprise just sketched was to reach this point without being ontologically committed to anything more than simple concreta. One wants to give voice to this by saying: sets and compound objects do not exist. But to say this would be to fall into contradiction. So we need to do something else to give voice to our minimal metaphysics.

What we need, therefore, is an expressive device that will allow us to articulate the situation. Recall that in the current setting, the requirement for ' $\phi$ ' to be true at $w$ is articulated in the first instance in terms of what $w F$-represents to be the case. The basic idea is to introduce an operator 'Fundamentally $\phi$ ' which will be true at a world $w$, just in case $w$ doesn't merely $F$ represent that the relevant conditions are met, but really represents that they are met, in the sense that the conditions hold at $w$. Thus, a world containing only microphysical simples might compound-represent the existence of tables, and this might be all that is required for the truth of 'there are tables'. But, the idea will be, 'Fundamentally, there are tables' should require that $w$ truly represent that there are tables, not merely compound-represent this. And so, as desired, this will be false at a world where only the simples exist.

It is one thing to lay out the general idea, another to characterize an object-language operator that works in this way. The technical puzzle is that in the gloss above, 'it is fundamentally the case that' is characterized by talking metalinguistically about what would happen under alternatives to the actual theory of requirements for the object language. And it is not straightforward to convert this into a characterization of an object-language operator.

However, we can finesse this issue by supplementing our theory in the following way. Let us suppose that one is tempted to allow talk of $F \mathrm{~s}$, via the following scheme (where $\mathcal{F}$ is a theory of $F \mathrm{~s})$ :

' $w F$-represents that $q$ ' is true iff there is some ' $p$ ', such that ' $[p]_{w}$ ' is true, and $\{$ ' $\tilde{p}$ ', $\mathcal{F}\} \Rightarrow{ }^{\prime} q$ '

This tells us what is $F$-represented at the possible worlds. But to define the Fundamentality operator, I propose that we add to the set of possible worlds a range of entities of another kind - one for each possible world (we can let $\sigma$ be a bijection from possible worlds onto these newly introduced entities). One might think of these as 'impossible worlds' or 'non-normal worlds'-but I do not want to be committed to any specific baggage such terminology might have. All that is required for present purposes is that these be entities which are distinct from the possible worlds - they might, for example, be natural numbers, or other abstracta with the same cardinality as the set of possible worlds - and that they have the properties that the following stipulative definition endows them with:

$$
\sigma(w) F \text {-represents that } q \text { iff }[q]_{w}
$$

The idea here is that $\sigma(w)$ pseudo-represents whatever is the case at $w . \sigma(w)$ is a 'faithful mirror' of $w$ : it lets us see what $w$ really thinks there is.

The advantage of introducing these faithful mirrors is that we can simply apply our existing theory of what is required for an object language sentence to be true at each one of them. For in 
the first instance, what it takes for $S$ to be true at $w$ is set out in terms of what $w F$-represents. As explained earlier, for possible worlds this corresponds to a requirement that $w$ represent things as being a certain way - but equally, in the case of these mirrors, this requirement that $\sigma(w) F$ represent that $p$ is just the demand that $w$ is such that $p$. Pseudo-requirements on mirrors just are requirements on the corresponding possible worlds. So, without having to change the theory of requirements at all, simply adding entities characterized as above to the space of worlds enables us indirectly to talk about what the truth-values of sentences at $w$ would be on a Quinean theory of requirements - for this is the net result of applying the non-Quinean theory of requirements to $\sigma(w)$.

The basic idea is therefore to think of 'It is fundamentally the case that' as a modal operator as follows:

'Fundamentally $\phi$ ' is true at $v, w$ iff ' $\phi$ ' is true at $v, \sigma(w) .{ }^{37}$

\subsection{Summary}

Kit Fine's recent defence of a distinction between what exists, and what really or fundamentally exists might be given a thoroughgoingly metaphysical reading. But it need not be. Unless we presuppose a Quinean setting, we cannot assume that we can read the ontological commitments of the world from their apparent subject-matter. 'There are rocks' might not require the existence of rocks, in order to be true. In such a setting, the operators really or fundamentally are indispensable conceptual tools: allowing us to give expression to genuine metaphysical theses amidst a thicket of true but metaphysically misleading existence claims.

I have illustrated this by sketching accounts of the worldly demands imposed by compoundobject and set-theoretic propositions. By constructing appropriate notions of pseudo-representation, and piggybacking on the Quinean theory, the ontology of a nominalist, mereologically nihilist world can be seen to support all the truths one could wish for. Clearly, the piggybacking method is extremely general: I envisage treatments of discourse about universals, propositions, fictional

\footnotetext{
${ }^{37}$ In fact, this will run into problems with iterations of the Fundamentality operator-since $\sigma(w)$ is not within the domain of $\sigma$, 'Fundamentally $\phi$ ' will be undefined at the mirror worlds. To remedy this, we need to characterize an appropriate accessibility relation: reflexive on the mirrors, and such that $w$ sees only $\sigma(w)$; we can then define Fundamentality using standard clauses for a modal operator.

Plausibly, the operator is hyperintensional. Our earlier picture motivates the view that (given the right setting) universal fusion will be necessarily the case: at any possible world, the existence of fusions requires no more than the existence of the simples themselves. But for fusions to exist at a mirror world, the world mirrored must genuinely represent the existence of compound entities. And there is no reason to think that condition will be met. Thus, it will be fundamentally the case that simples exist, and necessarily the case that if they exist they have a fusion; but not fundamentally the case that a fusion of the simples exists. Fundamentality will be a hyperintensional operator.

Even so, it remains unclear whether Fundamentality will be able to do the unificatory job envisaged for it earlier (to draw distinctions between elite and non-elite properties, operators and the like, as well as between elite and non-elite facts). Consider two possible accounts of what it takes for something to be grue. (1) the condition on $w$ for ' $x$ is grue' to be true at $w$ is $[x \text { is green }]_{w}^{*}$ and $[x \text { was examined before } t]_{w}^{*}$ or $[x \text { is blue }]_{w}^{*}$ and $[x$ was not examined before $t]_{w}^{*}$. (2) the condition on $w$ for ' $x$ is grue' to be true at $w$ is $[x \text { is grue }]_{w}^{*}$. Now, it may well be that no world is such that something is grue. If so, then given conditions of style (2) for grue, nothing will be fundamentally grue. But if worlds genuinely represent things as being green, and examined at various times, then given a style (1) treatment of the conditions for being grue, we will have things being fundamentally grue. The prospects for extracting an elite/non-elite distinction among properties given a type (1) analysis look grim. So the details matter-we need a theory of requirements of type (2) to sustain the promise of Fundamentality.

However, it is in the spirit of the theory of requirements I have latterly been exploring to go for a type (2) theory of requirements. And even if Fundamentality doesn't do every job one might have wished, that is not to say that the overall theory doesn't provide a unifying account. And indeed, the notion of genuine representation, [ $]_{w}$ may in effect be exactly the kind of fine-grained operator required for all these theoretical roles.)
} 
characters, possibilia, minor entities (e.g. shadows, holes), as well as compound objects and abstracta, could be dealt with satisfactorily in the same fashion: through construction of an appropriate pseudo-representation relation and the use of this to formulate a theory of requirements acceptable to one who is nihilistic about such entities.

One need not buy into these particular theories of requirements in order to appreciate the general moral (though I do regard the tactics illustrated here as a highly promising resource for non-error theoretic nihilists). I mentioned earlier paraphrases and non-piggybacking implementations of Rayo's machinery, which can be put forward as a theory of requirements for an apparently committal language. In that setting, as much as this, one has the need for expressive resources that allow us to articulate one's metaphysical claims. And for these purposes, we will always stand in need of something like the notion of what is really, as opposed to merely, the case. $^{38}$

\section{Postulationism and Interpretationism}

To this point, we have been developing a framework for understanding the distinction between fundamental and derivative truths. But that doesn't yet give us any guidance as to what the fundamental or derivative truths are. A similar point can be made, more narrowly, about the Rayo-style theories of ontological commitment described above: they provide a way of formulating Quinean and anti-Quinean theories of ontological commitment. But they don't tell us how to choose among them.

In these closing sections, I will look to combine the view on derivative truths developed above with an independently motivated view on metasemantics - the theory of how words acquire meaning. The upshot will be a story about how metaphysics and linguistic practice combine to fix what the ontological commitments of our language are, and hence, what is derivatively true. A side-effect will be that we can make sober sense of the idea of postulating certain objects into existence. On the basis of a minimal metaphysics where reality contains no sets or compound objects, we get an attractive picture whereby sets and gerrymandered fusions can be postulated into existence as and when required. That such a view flows naturally from the framework developed in this picture, and the minimal metaphysics described, lends considerable support for the overall package.

\subsection{Interpretationisms and charity}

A natural question is the following: what fixes the ontological commitments of our sentences? Faced with the choice between Quinean and anti-Quinean theories of requirements, what sort of considerations can we bring to bear?

This question is particularly pressing for the nihilist. For one might think that the Quinean theory has a claim to be the default view, not only because of its entrenchment in the literature,

\footnotetext{
${ }^{38}$ As well as giving an account of Fine's talk of fundamental and derivative truths, it is interesting to consider truth-making operators as presented in Melia (n.d.). I am not sure how to give a formal characterization of such an operator, but generally we can regard a proposition that (a) is really the case; and (b) articulates what is required for the truth of $q$; as making true $q$. Thus, that simples exist arranged table-wise truth-makes that tables exist (according to the theory of requirements given above). Parallel to truth-maker talk, we might introduce referencemaker talk. Thus, 'Billy' refers to Billy (the fusion of things $x x$ arranged Billy-wise), and the reference-maker in this case is just that the $x x$ are arranged Billy-wise (it is the reference-maker in the sense that, according to the above theory of requirements, this is the condition that the world must meet in order for the above reference relation to hold.
} 
but also because it just seems more commonsensical to think that, when people claim that tables and chairs exist, they are committing themselves to the real existence of tables and chairs.

I suppose it might be possible to take the correctness of this or that theory of requirements as brute. I dislike this approach, and can offer a more satisfying replacement. I regard the question: what fixes the ontological commitments of sentences? as answered as one part of the metasemantic project of saying what makes it the case that sentences have the truth-conditions that they do.

Consider again ordinary discourse about chairs. The datum is that people assent to sentences like 'there are chairs'. Supposing that reality contains only microscopic concreta, what would be the consequences of interpreting agents as uttering sentences whose truth requires that reality contain chairs and tables? The answer is clear: the sentences would be false. Thus, a principle of charity will incline us towards an ontologically non-committal reading of the sentences. ${ }^{39}$

The kind of metasemantic theory that brings considerations of charity most to the fore are interpretationisms. The general thought behind a principled interpretationism is this: the semantic facts are those described by the best theory of patterns of assent and dissent; where 'best' is cashed out in non-semantic terms. Factors that go toward making a theory best include: simplicity (minimizing the complexity of a theory, for example its syntactic complexity when spelled out in elite terms) and fit with the data (maximising the number of assented sentences represented as true). ${ }^{40}$

I want to suggest the following. There are costs associated with interpreting some discourse as ontologically non-committal, using the sort of machinery developed above. In particular, rather than using a simple notion of what is the case at a world, the semantic theory will be formulated using a more complex notion of pseudo-representation. So, all else equal, there is a bias in favour of interpreting discourse as committal.

But all else is not equal, if the committal interpretation of the discourse will make speakers persistently speak falsely. Compared to the massive lack of fit that a committal interpretation engenders, we can swallow the small decrease in simplicity that is required in order to generate a non-committal reading of the words.

Thus, in the absence of sets, there is pressure towards a non-committal interpretation of the set-theorist's language, by formulating the semantics in the first-instance in terms of setrepresentation, rather than representation proper. And, mutatis mutandis for discourse about the macroscopic, if all that really exists is at the microlevel.

\subsection{Postulationism}

One interesting result of these considerations, is that it seems we might be able to 'postulate into existence' new objects. Not into fundamental existence, of course: but nevertheless, our

\footnotetext{
${ }^{39}$ Matters may be different if we assume the folk go round saying things like: tables fundamentally exist; tables are part of fundamental reality. If so, and they mean the same thing by 'reality' as we do here, then in interpreting them in the non-committal way we will make at least some of their utterances false: the ones that make the distinctively philosophical claim that about the reality of ordinary objects. This is not to say that the odds are suddenly in favour of giving an error-theoretic account of chair-talk in such a population (after all, just because we can't render all of their chair-talk true, doesn't mean we should render all of it false!). But it certainly makes the non-committal and non-error theoretic interpretation less conclusively the best available option, given the competing virtues of the simple, Quinean theory. Of course, if people go round treating controversial philosophical claims as platitudes, then they really have only themselves to blame if they end up speaking falsely most of the time!

${ }^{40}$ I take Lewis (1975), Davidson (1974) to be paradigmatic metasemantic interpretationists. The view considered by Putnam (1980) and defended in Lewis (1984) under the label 'global descriptivism' is another variant. Williams (2007) gives an overview of interpretationisms. Williams (2005, ch 1,2) goes into more detail on the interpretationist metaphysics of semantic facts.
} 
activity can ensure the truth of statements such as 'there is an inaccessible cardinal'.

The just-so-story goes as follows. Suppose we have a community of mathematicians, who until time $T$ had contented themselves by speaking of only finite sets. At $T$, it strikes one of the community that it might be useful to think in terms of an infinite set. So, she lays down an axiom postulating the existence of an infinite set. The ensuing theory is so attractive that her community adopts the axiom in short order. And the set theorists begin to theorize about the infinite in the familiar way.

Before time $T$, the apparent ontological commitments of the community in question were just to a weak set theory we can call $Z F^{-}$. It will suffice, for purposes of charity, to interpret the discourse via a pseudo-representation relation constructed as follows:

- ' $w$ set $^{-}$-represents that $q$ ' is true iff there is some ' $p$ ', such that ' $[p]_{w}$ ' is true, and $\left\{\tilde{p}^{\prime}, Z F^{-}\right\} \Rightarrow ' q$ '

Considerations against excess complexity give us a principled reason against using some richer pseudo-representation to interpret this discourse. In particular, it gives reason to resist the use of the following:

- ' $w$ set ${ }^{+}$-represents that $q$ ' is true iff there is some ' $p$ ', such that ' $[p]_{w}$ ' is true, and $\left\{{ }^{\prime} \tilde{p}^{\prime}, Z F\right\} \Rightarrow$ ' $q$ '

After all, this is just that bit more complex a construction than the previous: and interpretationism councils us against needless complexity.

The situation changes, however, once the infinite set is postulated. For then, considerations of charity kick in to make set ${ }^{+}$-representation the better interpretative candidate. set $^{-}$representation is still simpler; but set $^{+}$-representation is able to render true far more of the set-theorist's discourse than its rival. Charity in this case trumps simplicity.

The story generalizes. Given the practice of working within ZFC, a set-theorist might start to whether there are sets that she cannot prove to exist. She might postulate at $T^{\prime}$, for example, the existence of the first inaccessible set. And, as in the case just considered, if her postulation is taken up, charity will override the extra complexity, and the correct interpretation will make-true the set-theoretic axioms.

Notice how this goes. Prior to $T$, it was true to claim (even with quantifiers 'wide open') that no infinite set exists. Prior to $T^{\prime}$, it was likewise true to claim that no inaccessible set exists. But once the practice of claiming there to be such sets gets entrenched, it will become true to assert the existence of infinite and inaccessible sets.

What goes in the case of set theory, may also go in the case of mereology. One way that mereological theories can differ from each other is over what principles of composition they embed. Universal fusion - that every collection of things have a mereological sum-is one such principle. Suppose (contrary to fact, perhaps) that there is a consensus in a community that gerrymandered entities such as Hirsch's 'incars' do not exist (even in the most unrestricted sense); but that medium-sized dry goods like rocks, chairs and tables do exist. It may be hard to spell out exactly what not-too-complex principles of composition would make these patterns of assent and dissent true (van Inwagen, 1990), but for the sake of argument let us suppose that some principle $P$ does the job, so that a charitable interpretation of the language can be given if we deploy a notion of compound-representation based on a mereological theory including $P$. Now, suppose that some metaphysically minded member of this community makes the daring postulation: incars exist. Impressed with the simplicity and philosophical utility of the theory that ensues, the community starts to talk in ways that require the existence of gruesome fusions. Then, interpretative charity (together, this time, with the attractive simplicity 
of the proposal) makes a compelling case for interpreting the language via a new compoundrepresentation relation replacing $P$ with universal fusion. Postulating gruesome fusions brings them into existence. ${ }^{41}$

\subsection{Limits on postulating}

Suppose one buys into the postulationism framework. One then wonders about the limits of the enterprise. Can one postulate into existence donkeys and kitchen tables? Can one, by postulating, make it the case that things have new properties? Can one postulate that lonely old women are witches, and by so-postulating, make it so ${ }^{42}$

One might think that such worries are reinforced by the appeals to charity above. Isn't there always a way to be maximally charitable — by choosing a suitably devious pseudo-representation relation? Suppose, for example, that in reality, Tigers are striped, but I utter the words 'Tigers are not striped'. Now, since @ genuinely represents that Tigers are striped, it will contrarepresent, in the sense defined earlier, that tigers are not striped. So a theory of requirements formulated in terms of contra-representation rather than representation appears to be able to give a charitable interpretation of this language-user.

Likewise, suppose that the actual world doesn't represent anything as being a witch. Nothing seems to prevent us from setting up a stipulated notion of witch-representation, such that $\mathrm{w}$ witch-represents that $q$ iff $w$ represents some $p$ such that $p$ and the thesis that lonely old women are witches entails that $q$. Won't it then follow that, using this notion, we can make the case that 'witches exist" are true, with this truth just requiring that the reality contain lonely old women. Again, charity would appear to push us towards accepting such an interpretation as the right one.

I take it that it would be terrible if we could trivialize issues like this. But I suggest there is nothing per se bad with witch-representation or contra-representation, or with the theory of requirements built from them. The appropriate reaction to pointing out that these are possible interpretations, is to explain on independently motivated grounds why they are bad and unintended interpretations of the language we use.

Above, I mentioned the concern that charity might give us pro tanto reason to favour the devious theories just mentioned. But the interpretationist principles for fixing the right semantic theory apply at a level of whole languages rather than individual utterances. Thus, while appealing to a theory of requirements embedding contra-representation might be charitable insofar as it renders-true an utterance of 'tigers don't have stripes', it would be horrendously uncharitable in that all sorts of platitudinous utterances (e.g. 'there is a table over there'; 'you look tired today', etc) would, by the lights of the contra-representation theory, be taken to make demands on the world exactly opposite to those we would normally taken them to have. So though one utterance is represented as true which would otherwise be represented as false by lights of devious theory, the theory would be overwhelmingly uncharitable when we consider its predictions for all utterances, rather than a single isolated one. Even just sticking with the charity element of the interpretationist metasemantics, therefore, we have independent reason to reject the contra-representation based theory of requirements.

The second case mentioned is more subtle. We could lay down a theory of requirements which inter alia would make the requirements for the truth of 'witches exist' be the existence of lonely old women. The point is again that this is likely to be a bad theory of requirements

\footnotetext{
${ }^{41}$ Compare Fine (2006): thinking through his picture of unrestricted quantification led me to the above ideas. Indeed, much of this essay can be read as an attempt to find metaphysically deflationary ways of spelling out some of the views he there articulates.

${ }^{42}$ Thanks to Andrew McGonigal for discussion.
} 
from the interpretationist point of view. It would render false, for example, many of the usual platitudes about witches as traditionally conceived: that they have supernatural powers, that they are in league with the devil. The point about witch-representation, as with contra-representation, is not that there is anything in principle wrong with its construction, or using it within a theory of requirements, but that, in fact, there is no obvious role for it within a plausible overall theory of requirements for witch-talk. ${ }^{43}$

\subsection{Faultless disagreement?}

The following situation can arise in mathematical discourse. My friends and I lay down one sort of axiom (governing sets, say). You and yours lay down a different, incompatible one. Both discourses are coherent, and perhaps both are mathematically interesting. Perhaps I am in favour of the generalized continuum hypothesis $\mathrm{GCH}$; and you are investigating an interesting way in which it might fail.

Once upon a time, we spoke the same language. The pseudo-representation relation appropriate to interpreting each of us was, perhaps:

- ' $w$ set ${ }^{+}$-represents that $q$ ' is true iff there is some ' $p$ ', such that ' $w$ represents that $p$ ' is true, and $\left\{{ }^{\prime} \tilde{p} ', Z F\right\} \Rightarrow$ ' $q$ '

But by laying down and entrenching $G C H$, I made it the case that the best interpretation of my words goes via the following:

- ' $w$ set*-represents that $q$ ' is true iff there is some ' $p$ ', such that ' $w$ represents that $p$ ' is true, and $\left\{{ }^{\prime} \tilde{p}, Z F+G C H\right\} \Rightarrow$ ' $q$ '

Your investigation of a failure of $G C H$ may mean that you are best interpreted via the following (where $G C H^{\prime}$ is some specific denial of $G C H$ ):

- ' $w$ set**-represents that $q$ ' is true iff there is some ' $p$ ', such that ' $w$ represents that $p$ ' is true, and $\left\{{ }^{\prime} \tilde{p},, Z F+G C H^{\prime}\right\} \Rightarrow$ ' $q$ '

\footnotetext{
${ }^{43}$ One issue this raises is exactly to what the interpretationist metasemantics is to be applied. Following Lewis (1974), I have been assuming that it is a story about what fixes the content (and so, en passant, the theory of requirements) for a communal language. I take it to be uncontroversial that an interpretation that made 'witches existed, and were lonely old women' and the like true, but 'witches were evil, and in league with the devil' and the like, false, would overall be an uncharitable theory. But this is in part an empirical claim about what the pattern of usage of 'witches' is among English speakers. One can certainly imagine situations where the idea of witches as wise women gained folk currency, and the propaganda that witches were evil was regarded as debunked in the light of historical evidence. In that situation, it might well be that the theory of requirements given is unobjectionable (one can also imagine an intermediate situation in which is indeterminate how to represent the case). This all seems as it should be. What seems important is that the current theory gives no way to simultaneously (a) postulate witches into existence; (b) maintain an analytic connection between witches and traditional witchy activities and characteristics. And I cannot see that there is any threat that the interpretationist metasemantics makes bad predictions here.

There is, of course, more to be said on the details of the metasemantics itself, which for reasons of space I am suppressing here. In particular, there are questions about whether we might try to apply it at the level of idiolects rather than communal languages; how exactly charity is to be cashed out (is it really just a matter of maximizing the true utterances and minimizing the false ones? Or should it for example be articulated in something like the way that Lewis (1974) suggests - as the constraint on semantic theory that it match the sentence-proposition pairs that are arrived at by looking at conventions of truthfulness governing utterances.
} 
Each of us speaks truly, therefore, within his or her own context.

Do we nevertheless disagree? In one sense, clearly not. For what the truth of GCH in my mouth requires of the world is different from what the truth of $\mathrm{GCH}$ in your mouth would require. So it would be pointless us engaging in some debate centred on the truth or falsity of what we say (rather than, say, the coherence of the frameworks we use, or their interest and usefulness). Each of us, after all, speaks truly, and the other can appreciate this. But this lack of disagreement should not be thought of as us 'speaking past each other' in some standard sense. We are not using the word 'set' ambiguously (or at least, it is yet to be argued that we are). In particular, there is no reason to deny that when I talk of the null set, and you talk of the null set, its singleton, and so on, we are both referring to the same individuals.

As before, similar situations arise in the mereological case. Debates between communities with different beliefs about what compound objects exist, turn out to be empty.

\section{Conclusion}

Quinean orthodoxy collapses the distinction between what there is, and what there is in reality. In the first half of this essay, I formulated the Quinean orthodoxy, and some rivals. Operators such as 'Really' and 'Fundamentality' become indispensable to expressing the nihilist metaphysics; though they themselves do not correspond to any metaphysical distinction.

This left open the question: which of these theories is the right one for the language we speak? Nihilists, of various forms, might prefer it if the anti-Quinean story held: for then they would be able to avail themselves of a non-error theoretic account of the discourse in question. But have they any principled reasons for thinking that ontological commitments are this thin? In the second half of this essay, I suggested that a general interpretationist metasemantics will return plausible and attractive verdicts on the ontological commitments on natural languages.

We have throughout focused on two nihilisms: a mereological nihilism that denies the real existence of compound objects; and a set-theoretic nihilism that insists that the only real existents are concrete. I identified a general style for formulating a nihilist-friendly theory of requirements which has application far beyond these two cases; and which is compatible with many variations on the theories here studied.

If the view of metaphysics sketched here is the right one, that discipline falls into two halves. Questions of what sets exists, of the special composition question and the like may well turn out to be issues for 'metaphysics lite', and best approached through the philosophy of language. In addition, we have metaphysics proper: the study of the nature of reality itself. Both are intriguing intellectual disciplines; but, on this view, both have suffered from an unwarranted conflation. 


\section{A Appendix: Arbitrary worlds}

The languages that we are explicitly studying in this paper are all non-modal, in the sense that they do not contain world-shifting operators. This simplifies the task of interpreting the theorems output by the theory of requirements considerably. For if the basic axioms for what $e$ refers to at $w$ are in terms of bracketed formulae of the form $[p]_{w}$, and if there are no devices in the languages whose compositional role is to shift the world-parameter, then the statement of what reality must be like for a sentence to be true will be take a simple form-there will be no bracketed formulae relativized to anything other than @. Since I earlier described how to understand what requirements are imposed by such statements, the story is complete for present purposes.

Concentrating on a fragment of a language can often be illuminating. But ultimately, we want a theory of requirements for natural language, which presumably does include worldshifting operators. So while the story in the paper is complete by its own lights, it is worth considering how it should be extended into a wider setting.

To pose her puzzle, the objector will appeal to a natural thought about what sort of clause should govern modal operators:

' $\nabla p$ ' is true at $a, w$ iff there is some $u$ such that ' $p$ ' is true at $a, u$

Given this, the condition for, for example, ' $\nabla$, Billy sits' is that there be some $u$ and an $x$ such that (i) $[\dot{x}=\text { Billy }]_{u}$ and (ii) $x \in\left\{y:[\operatorname{sits}(\dot{x})]_{u}\right\}$. The challenge is then to say what requirement on reality this expresses.

By the lights of the recipe given earlier, what does reality have to be like for this clause to be satisfied? Well, read at face value, it could be any way at all so long as a certain condition holds - where that condition is a long statement about the existence of worlds that represent such-and-such. What we get by taking our earlier suggestion at face-value and applying it to this sentence, is that either the requirement on reality is trivial (if a certain $q$ is true) or impossible to meet (if $q$ is false). Arguably this does assign the correct truth-conditions to modal statements. ${ }^{44}$

To expand: the general role of a theory of requirements is to bring to bear whatever expressive resources are needed to express complex and coordinated demands on the world. Certain things need to be presupposed in order that that coordinating function works. For example, if there were no sets, then it would be bad to use set theoretic resources to express the requirements on the world for 'Billy exists' to be true. For various $p$, we need to presuppose the truth of $p$ in order to say what the truth of $S$ demands of reality. That should not be conflated with the theory including that reality be such that $p$ among the requirements for $S$ to be true-that would make the existence of sets part of what is required for 'Billy sits' to be true.

Now consider a situation where the condition expressing what is demanded by $S$ 's truth is expressed by a formula of the form $q \&[p] @$, where $q$ is free of bracketed formulae relativized to @. View this as a way of formulating a complex, coordinated requirement on reality-in

\footnotetext{
${ }^{44}$ It will work so long as modal statements are non-contingent—for the trivial/impossible demands correspond to them being vacuously true. In an S5 setting for metaphysical modality this is exactly what we get. This is no surprise, since the simple clause for $\diamond$ given earlier wouldn't be appropriate to a more nuanced modal logic.

In a non-S5 setting, the natural thought is to appeal to an accessibility relation in the clause for possibility. So ' $\nabla p$ ' will be true at $w$ iff there is some $u$ that is accessible from $w$ such that ' $p$ ' is true at $a, u$. Notice that $u$ being accessible from @ might well impose requirements on @. For example, for a nomic modality, for $u$ to be accessible from $w$, it might be necessary and sufficient that some laws, $L$ exist, such that $[\mathrm{L} \text { are the laws of nature }]_{w}$ and $[\mathrm{L}$ are never violated $]_{u}$. This will then make the demands on $u$ non-trivial. In effect, the requirements that @ must meet for some $q$ to be nomically possible at @, is that the laws of nature meet some complex specification that the theory of requirements specifies. This seems like an intuitively natural result.
} 
this case, what the requirement in fact is coordinated to $q$ 's truth. if $q$ is true, then the clause is satisfied iff reality is such that $p$. If the $q$ is false, then the condition can never be satisfied-so overall the demands are impossible to meet.

An extreme case would be where $p$ is something tautologous, or where the clause $[p]_{@}$ is left out altogether. The coordinated requirement on reality is then vacuously met if $q$ is true, and vacuously unmet if $q$ is false. So in this extreme case, clauses can still impose (coordinated) requirements on reality-either trivial or impossible requirements, according to whether $q$ is true or false.

Interpreted in this way, it might be that the obvious extension of the theory of requirements to the modal case says nothing objectionable. But that isn't to say that it says anything particularly illuminating about the modal. Rayo (MS.) advocates a different strategy for spelling out in non-modal terms what is required for a modal statement to be true. ${ }^{45}$

\section{References}

Armstrong, D. M. 1989. Universals: An opinionated introduction. Boulder: Colorado: Westview Press.

Azzouni, Jody. 2004. Deflating existential consequence: a case for nominalism. Oxford: Oxford University Press.

Cameron, Ross. 2008a. 'Truthmakers and ontological commitment: or, how to deal with complex objects and mathematical ontology without getting into trouble'. Philosophical studies, 140(1), 1-18.

Cameron, Ross. 2008b. 'Truthmakers, realism and ontology'. Pages 107-208 of: Le Poidevin, Robin (ed), Being: Contemporary developments in metaphysics. Royal Institute of Philosophy Supplement, vol. 83. Cambridge: Cambridge University Press.

Chalmers, David. 2002. 'Does conceivability entail possibility'. Pages 145-200 of: Gendler, Tamar, \& Hawthorne, John (eds), Conceivability and possibility.

Davidson, Donald. 1974. 'Belief and the basis of meaning'. Synthese, 27, 309-23. Reprinted in Davidson, Inquiries into Truth and Interpretation (Oxford University Press, Oxford: 1980) pp.141-154.

Dorr, Cian. 2002. 'The simplicity of everything'. PhD Dissertation, Princeton University. Online at http://www.pitt.edu/ csd6/.

Dorr, Cian, \& Rosen, Gideon. 2002. 'Composition as a fiction'. In: The blackwell guide to metaphysics. Oxford: Blackwell.

\footnotetext{
${ }^{45}$ The material from which this paper is drawn has been presented at the University of Leeds senior seminar, at the Philosophy Club at the University of Oxford, the Leeds CMM workshop 'Structure in metaphysics', and a St Andrews workshop on 'The metaphysics of being basic' (where a fused version of this paper and (Cameron, 2008a) was presented). An early version of this paper formed part of the underground programme of the INPC metametaphysics conference in Boise, Idaho in 2007. Thanks are owed to everyone with whom I've discussed this, either at these events or informally. A horribly incomplete list: Elizabeth Barnes, Antony Eagle, Matti Eklund, Daniel Isaacson, Katherine Hawley, Dan Lopez de Sa, Jonathan Lowe, Ofra Magidor, Kris McDaniel, Joseph Melia, Andrew McGonigal, David Nicolas, Marcus Rossberg, Robert Schwarzkopff, Oliver Pooley, Gabriel Uzquiano and Jason Turner. Especial thanks are owed to Ross Cameron and Agustín Rayo.
} 
Field, Hartry H. 1998. 'Which undecidable mathematical sentences have determinate truth values?'. Pages 291-310 of: Dales, H. Garth, \& Oliveri, Gianluigi (eds), Truth in mathematics. Oxford University Press. Reprinted with postscript on categoricity arguments in Field (2001) pp. 332-360.

Fine, Kit. 2001. 'The question of realism'. Philosopher's imprint, $\mathbf{1}$.

Fine, Kit. 2005. Tense and modality. Oxford: OUP.

Fine, Kit. 2006. 'Relatively unrestricted quantification'. In: Rayo, Agustín, \& Uzquiano, Gabriel (eds), Absolute generality. Oxford: Oxford University Press.

Hawthorne, John. 2002. 'Deeply contingent a priori knowledge'. Philosophy and phenomenological research, 65(2), 247-269.

Hirsch, Eli. 1993. Dividing reality. New York: Oxford University Press.

Kelly, Thomas. 2005. 'Moorean facts and belief revision, or Can the skeptic win?'. Philosophical perspectives, 179-209.

Larson, Richard K., \& Segal, Gabriel. 1995. Knowledge of meaning. Cambridge, MA: MIT Press.

Lewis, David K. 1974. 'Radical interpretation'. Synthese, 23, 331-44. Reprinted in Lewis, Philosophical Papers I (Oxford University Press, 1983) 108-18.

Lewis, David K. 1975. 'Language and languages'. Pages 3-35 of: Minnesota studies in the philosophy of science, vol. VII. University of Minnesota Press. Reprinted in Lewis, Philosophical Papers I (Oxford University Press, 1983) 163-88.

Lewis, David K. 1983. 'New work for a theory of universals'. Australasian journal of philosophy, 61, 343-377. Reprinted in Lewis, Papers on Metaphysics and Epistemology (Cambridge University Press, 1999) 8-55.

Lewis, David K. 1984. 'Putnam's paradox'. Australasian journal of philosophy, 62(3), 221-36. Reprinted in Lewis, Papers on Metaphysics and Epistemology (Cambridge University Press, 1999) 56-77.

McGee, Vann. 1997. 'How we learn mathematical language'. Philosophical review, 106, 35-68.

Melia, Joseph. 'Truthmaking without truthmakers'. In: Beebee, Helen, \& Dodd, Julian (eds), Truthmakers: the contemporary debate. Oxford University Press.

Merricks, Trenton. 2001. Objects and persons. Oxford: Clarendon Press.

Putnam, Hilary. 1980. 'Models and reality'. The journal of symbolic logic, 45(3), 421-444. Reprinted in Benacerraf and Putnam (eds.) Philosophy of Mathematics: Selected readings, second edition (Cambridge University Press, Cambridge: 1983).

Quine, W. V. 1953. From a logical point of view. Oxford: Oxford University Press.

Rayo, Agustín. 2007. 'Ontological commitment'. Philosophy compass, 2(3), 428-444.

Rayo, Agustín. 2008. 'On specifying truth-conditions'. Philosophical review, 117, 385-443. 
Rayo, Agustín. MS.. 'An account of possibility'.

Shapiro, Stewart. 1991. Foundations without foundationalism: A case for second-order logic. Oxford logic guides ; 17. Oxford: Clarendon Press.

Sider, Ted. 2007a. 'Parthood'. Philosophical review, 116, 51-91.

Sider, Ted. 2007b. 'What disputes are substantive?'. ms.

Sider, Ted. 2009. 'Ontological realism'. In: Chalmers, David, Manley, David, \& Wasserman, Ryan (eds), Metametaphysics. Oxford: OUP.

Soames, Scott. 1989. 'Semantics and semantic competence'. Philosophical perspectives, 3, $575-596$.

Uzquiano, Gabriel. 2004. 'Plurals and simples'. The monist, 87(3).

van Inwagen, Peter. 1990. Material beings. Ithaca and London: Cornell University Press.

Williams, J. R. G. 2005. The inscrutability of reference. Ph.D. Thesis, University of St Andrews.

Williams, J. R. G. 2007. 'Eligibility and inscrutability'. Philosophical review, 116(3), 361-399.

Williams, J. R. G. 2008. 'Working parts'. In: Le Poidevin, Robin (ed), Being: Contemporary developments in metaphysics. Royal Institute of Philosophy Supplement, vol. 83. Cambridge: Cambridge University Press.

Williamson, Timothy. 2003. 'Everything'. Philosophical perspectives, 17, 415-465.

Yablo, Stephen. 2000. 'A paradox of existence'. In: Hofweber, T. (ed), Empty names, fiction and the puzzle of existence. CSLI.

Yablo, Stephen. 2001. 'Go figure: A path through fictionalism'. Midwest studies in philosophy, 25, 72-102.

Yablo, Stephen. 2006. 'Non-catastrophic presupposition failure'. In: A., Byrne, \& Thomson, J. (eds), Content and modality. OUP. 